\title{
Mechanism of the natural product moracin-O derived MO-460 and its targeting protein hnRNPA2B1 on HIF-1a inhibition
}

\author{
Nak-Kyun Soung $\mathbb{0}^{1,2}$, Hye-Min Kim 1,2, Yukihiro Asami ${ }^{1,3,7}$, Dong Hyun Kim $\mathbb{1}^{1,2}$, Yangrae Cho ${ }^{1}$, Ravi Naik ${ }^{4}$, Yerin Jang ${ }^{4}$, \\ Kusic Jang ${ }^{4}$, Ho Jin Han ${ }^{1,2}$, Srinivas Rao Ganipisetti ${ }^{1}$, Hyunjoo Cha-Molstad ${ }^{1}$, Joonsung Hwang ${ }^{1}$, Kyung Ho Lee ${ }^{1}$, \\ Sung-Kyun Ko $\mathbb{D}^{1,2}$, Jae-Hyuk Jang $\mathbb{D}^{1,2}$, In-Ja Ryoo ${ }^{1}$, Yong Tae Kwon ${ }^{5}$, Kyung Sang Lee ${ }^{6}$, Hiroyuki Osada ${ }^{3}$, Kyeong Lee ${ }^{4}$, \\ Bo Yeon Kim ${ }^{1,2}$ and Jong Seog Ahn ${ }^{1,2}$
}

\begin{abstract}
Hypoxia-inducible factor-1a (HIF-1a) mediates tumor cell adaptation to hypoxic conditions and is a potentially important anticancer therapeutic target. We previously developed a method for synthesizing a benzofuran-based natural product, (R)-(-)-moracin-O, and obtained a novel potent analog, MO-460 that suppresses the accumulation of HIF-1a in Hep3B cells. However, the molecular target and underlying mechanism of action of MO-460 remained unclear. In the current study, we identified heterogeneous nuclear ribonucleoprotein A2B1 (hnRNPA2B1) as a molecular target of MO-460. MO-460 inhibits the initiation of HIF-1a translation by binding to the C-terminal glycinerich domain of hnRNPA2B1 and inhibiting its subsequent binding to the 3'-untranslated region of HIF-1a mRNA. Moreover, MO-460 suppresses HIF-1a protein synthesis under hypoxic conditions and induces the accumulation of stress granules. The data provided here suggest that hnRNPA2B1 serves as a crucial molecular target in hypoxiainduced tumor survival and thus offer an avenue for the development of novel anticancer therapies.
\end{abstract}

\section{Introduction}

Rapid proliferation of cells in solid tumors causes varying degrees of hypoxia in living tissue ${ }^{1}$. Cancer cells under hypoxic conditions accumulate a range of proteins through transcriptional induction, which promotes the growth of tumor tissue and provides resistance to cell death. These proteins play critical roles in angiogenesis, cell proliferation, glucose uptake, apoptosis, and

\footnotetext{
Correspondence: Jong Seog Ahn (jsahn@kribb.re.kr) or Bo Yeon Kim (bykim@kribb.re.kr) or Kyeong Lee (kaylee@dongguk.edu)

'Anticancer Agent Research Center, Korea Research Institute of Bioscience and Biotechnology, Cheongju 28116, Korea

${ }^{2}$ Department of Biomolecular Science, University of Science and Technology, Daejeon 34113, Korea

Full list of author information is available at the end of the article.

These authors contributed equally: Nak-Kyun Soung, Hye-Min Kim, Yukihiro Asami
}

metastasis $^{2-4}$. The transcriptional induction of these genes is mediated by a master regulator, the transcription factor hypoxia-inducible factor (HIF)- $1 \alpha^{1}$, and results in the selection of cancer cells that are adapted to hypoxic conditions. The presence of active HIF- $1 \alpha$ and subsequent induction of its downstream genes also promote cancer cell resistance to chemotherapy through various cellular responses (e.g., suppressing apoptosis ${ }^{5}$, bypassing senescence $^{6,7}$, altering cellular metabolism ${ }^{8}$, increasing drug efflux $\left.^{9}\right)$. Thus, the inhibition of HIF- $1 \alpha$ activity has attracted considerable interest by those looking to develop efficient therapeutic strategies for various solid cancers. The HIF-1 transcriptional complex is a heterodimeric protein composed of HIF- $1 \alpha$ and HIF- $1 \beta$ subunits. The alpha subunit is continuously transcribed and translated and its protein stability is regulated by oxygen levels in the 
host tissue ${ }^{2}$. HIF-1 transcriptional complex activity is regulated by the stability of the alpha subunit, which accumulates under hypoxic conditions, but is rapidly degraded under normoxic conditions, whereas the levels of the beta subunit do not fluctuate. This accumulation of HIF- $1 \alpha$ is a prerequisite for its activity.

A growing number of small molecules have been shown to inhibit HIF- $1 \alpha$ activity through a wide variety of molecular mechanisms (e.g., a reduction in HIF- $1 \alpha$ levels by inhibiting its synthesis or promoting its degradation, reductions in HIF-1 activity through impaired heterodimerization of the two subunits, reduced DNA binding, and decreased transactivation ${ }^{10}$ ). The small molecule geldanamycin promotes HIF- $1 \alpha$ degradation independently of the canonical HIF- $1 \alpha$ degradation pathway ${ }^{11}$. The small molecules PX-478 (HIF translation) and BAY872243 inhibit HIF-1 activity and are under investigation in clinical trials for the treatment of cancer ${ }^{12,13}$. (R)$(-)$-moracin-O, with its arylbenzofuran ring, is a natural product isolated from Morus species that exerts potent inhibitory effects on HIF- $1 \alpha$ accumulation under hypoxic conditions $^{14}$. The absolute configuration of naturally occurring (R)-(-)-moracin-O was previously determined and its first total synthesis was subsequently achieved ${ }^{15}$. A systematic analysis of the structure-activity relationship of (R)-(-)-moracin-O during that study led to the discovery of MO-460, i.e., (R)-4-[6-(1-hydroxy-1- parent compound $^{16}$.

The objectives of the current study were to identify the molecular target(s) of MO-460 and to characterize the molecular mechanism of its inhibitory effect on HIF-1 $\alpha$; we used several approaches. These approaches included an affinity capture method followed by identification of putative target proteins using mass spectrometry, a chemical-protein binding assay, and conventional biological assays. We found that MO-460 did not directly interact with HIF-1 $\alpha$ protein. Rather, it inhibited HIF- $1 \alpha$ accumulation by interacting with the heterogeneous nuclear ribonucleoprotein A2/B1 (hnRNPA2B1), which was previously unknown in the regulatory pathways of HIF- $1 \alpha$ synthesis. hnRNPA2B1 is a member of the hnRNP family of RNA binding proteins and plays key roles in multiple aspects of nucleic acid metabolism (e.g., alternative splicing ${ }^{17,18}$, mRNA trafficking ${ }^{19}$, telomere biogenesis $^{20,21}$, and transcriptional and translational regulation $\left.^{22,23}\right)$. HnRNPA2B1 is also involved in apoptosis and epithelial-to-mesenchymal transition (EMT) ${ }^{24}$. Moreover, it is overexpressed in several cancers, including glioblastoma, breast, and lung, and its expression level is positively correlated with poor prognosis ${ }^{24,25}$. Therefore, it is used as a new target for cancer therapy and a biomarker for cancer diagnosis ${ }^{26,27}$. Herein, the identification of this novel molecular target of MO-460 and its mode of action creates new potential avenues for cancer treatment.
In addition, MO-460, a small molecule targeting HIF- $1 \alpha$ under hypoxia, merits further development as an anticancer drug.

\section{Materials and methods \\ Synthesis of MO-460 and its biotin conjugated form analogues (Biotin linked MO-460)}

Please see online Supplementary Materials and Methods 1.

\section{Cell culture, antibodies, and siRNA transfection}

Hep3B and HEK293Tcells were purchased from American Type Culture Collection (ATCC) (Manassas, VA) in April 2013. Cells were passaged for less than 2 months before resuscitation for this work. Cells were routinely tested for mycoplasma contamination using the e-Myco Mycoplasma PCR Detection Kit (iNtRon Biotech.). The last test was done in December 2016. All cell lines were revived every 2 to 3 months. Cells were cultured as recommended by the ATCC. Transfection was routinely carried out with HiPerFect (Qiagen). Hep3B cells $\left(5 \times 10^{4}\right.$ cells $\left./ \mathrm{mL}\right)$ were seeded in 12 -well dishes and incubated for $12 \mathrm{~h}$. The cells were then transfected with or without 200 pmol of siRNAs using HiPerFect and incubated for $48 \mathrm{~h}$ with or without $200 \mu \mathrm{M} \mathrm{CoCl}_{2}$. All antibodies used in this study are listed in Supplementary Materials and Methods 2.

\section{Plasmid construction}

Detailed information on the construction of various plasmids and production of the lentivirus are described in the Supplementary Materials and Methods 3. All RNAi target products and sequences used in this study are listed in Supplementary Materials and Methods 4.

\section{Anti-hnRNPA2B1 antibody generation}

Bacterial His-tagged hnRNPA2B1, purified as described above, was injected into BALB/c mice. Hybridomas were prepared by fusing spleen cells with cells of myeloma line SP2/0-Ag14 using previously described procedures ${ }^{26}$. Enzyme-linked immunosorbent assays (ELISA) were performed to insure that each monoclonal antibody selected reacted exclusively with hnRNPA2B1. The prepared antibodies were available for immunoblotting (IB), immunoprecipitation and immunocytochemistry (ICC).

\section{Detection of binding proteins for Biotin-MO-460}

We synthesized biotinylated MO-460 using a recently reported method ${ }^{15}$. Fractionation and enrichment of cytosol and nuclei were performed as described previously $^{28}$. Briefly, Hep3B (Human hepatocyte cancer cell line) was harvested and washed twice with PBS after treatment with $200 \mu \mathrm{M}$ of $\mathrm{CoCl}_{2}$ for $24 \mathrm{~h}$, and then 
resuspended in lysis buffer [10 mM HEPES pH 7.9, 10 mM KCl, 0.1 mM EGTA, 0.1 mM EDTA, 0.5 mM PMSF, $0.025 \%$ 2-Mercaptoethanol, $1.6 \% \mathrm{NP}-40$, and protease inhibitor cocktail]. After cell lysis and homogenization by vortexing for $10 \mathrm{~s}$, the insoluble material was removed by centrifugation. The supernatant was collected as a cytosol-enriched lysate. The pellet was resuspended in nuclear extract buffer [20 mM HEPES pH 7.9, $400 \mathrm{mM}$ $\mathrm{NaCl}, 1 \mathrm{mM}$ EGTA, $1 \mathrm{mM}$ EDTA, $1 \mathrm{mM}$ DTT, $1 \mathrm{mM}$ PMSF, protease inhibitor cocktail]. The pellet was then vortexed vigorously at $4{ }^{\circ} \mathrm{C}$ to separate the insoluble material. After the cytosol-enriched lysate $(97.9 \mu \mathrm{g}$ of protein) and the nuclei-enriched lysate $(67.5 \mu \mathrm{g}$ of protein) were precleared by incubation with NeutrAvidine ${ }^{\mathrm{TM}}$ agarose-resins (Thermo Scientific) that were conjugated with biotin-linker (cytosol fraction: $600 \mu \mathrm{M}$, nuclear fraction: $1200 \mu \mathrm{M}$ ) for $12 \mathrm{~h}$ at $4{ }^{\circ} \mathrm{C}$, the cleared cell lysate was incubated with NeutrAvidine ${ }^{\mathrm{TM}}$ agarose-resins bound -Biotin-MO-460 (cytosol fraction: $200 \mu \mathrm{M}$, nuclear fraction: $400 \mu \mathrm{M}$ ) for $16 \mathrm{~h}$ at $4{ }^{\circ} \mathrm{C}$, respectively. The reacted samples were washed three times with binding buffer [10 mM HEPES $\mathrm{pH} 7.9,10 \mathrm{mM} \mathrm{KCl}, 0.1$ mM EGTA, $0.1 \mathrm{mM}$ EDTA, $0.5 \mathrm{mM}$ PMSF, 0.025\% 2Mercaptoethanol, and protease inhibitor cocktail] and the bound proteins eluted with SDS-PAGE sample buffer. The proteins were then separated on a 4-20\% SDSpolyacrylamide gradient gel and visualized using a silver staining kit (Thermo Scientific).

\section{Identification of binding proteins for Biotin-MO-460}

To identify the binding proteins, we recovered prominent protein-bands from biotin-MO-460 regions and biotin-linker regions (same-sized areas) in the SDSpolyacrylamide gel. The bands were reduced in 1,4dithiothreitol $(10 \mathrm{mM})$, alkylated with iodoacetamide (50 $\mathrm{mM})$, and then washed, dried, and rehydrated in trypsin solution $(12 \mathrm{ng} / \mu \mathrm{L})$ on ice for $1 \mathrm{~h}$. After adding $20 \mu \mathrm{L}$ of ammonium bicarbonate $(50 \mathrm{mM})$, samples were digested overnight at $37^{\circ} \mathrm{C}$ and the peptides extracted and dried. The dried peptides were rehydrated with a solution of 20 $\mathrm{L}$ of $0.1 \%$ formic acid and $2 \%$ acetonitrile $(\mathrm{ACN})$. Eight microliters of the resulting peptide mixture were injected onto a nano acquity LC system (Waters Corp. Manchester, United Kingdom). The peptides were separated on a $1.7 \mu \mathrm{m}, 75 \mu \mathrm{m} \times 150 \mathrm{~mm}$ BEH C-18 column (Waters Corp. Manchester, United Kingdom). The gradient (Solution A: $0.1 \%$ formic acid, solution B: $0.1 \%$ formic acid, $100 \% \mathrm{ACN}$ ) started at $5 \%$ and ended at $40 \% \mathrm{~B}$ after $45 \mathrm{~min}$. MS and MS/MS data were acquired using a QTOF Premier mass spectrometer (Waters Corp., Micromass, Manchester, UK). Double- and triple-charged peptide ions were automatically selected by MassLynx software and fragmented. MS data were processed and peak lists for protein identifications by database searches were generated by PLGS software. Database searches were carried out with MASCOT server version 2.2.0 using the NCBInr protein database. The peptide tolerance was set at $30 \mathrm{ppm}$ and the MS/MS tolerance to $0.1 \mathrm{Da}$.

\section{In vitro pull-down assay}

HEK293T cells were cultured in DMEM medium supplemented with $10 \%$ fetal bovine serum in a humidified atmosphere containing $5 \% \mathrm{CO}_{2}$. The cells were transfected with C-terminal Myc/DDK-tagged hnRNPA2B1 constructs. Recombinant protein was captured with an anti-DDK affinity column followed by conventional chromatography. A streptavidin-conjugated biotin linker was used as a control or streptavidin-conjugated biotinylated MO-460 were treated with $5 \%$ bovine serum albumin in PBS for $1 \mathrm{~h}$ at room temperature. Myc/DDKtagged hnRNPA2B1 protein (1 ug) was incubated with streptavidin-conjugated biotin linker $(1,200 \mu \mathrm{M})$ or streptavidin-conjugated biotinylated MO-460 $(400 \mu \mathrm{M})$ in the presence or absence of MO-460 $(400 \mu \mathrm{g})$ in binding buffer for $6 \mathrm{~h}$ at $4{ }^{\circ} \mathrm{C}$. The reacted beads were washed with binding buffer [10 mM HEPES $\mathrm{pH} 7.9,10 \mathrm{mM} \mathrm{KCl}, 0.1$ mM EGTA, 0.1 mM EDTA, 0.5 mM PMSF, 0.025\% 2mercaptoethanol, and protease inhibitor cocktail] and the bound proteins eluted with SDS/PAGE sample buffer. Proteins were resolved by SDS/PAGE and detected by silver staining.

\section{Analysis of the interaction between MO-460 and the hnRNPA2B1 binding region using the optical sensor}

The binding capacity of hnRNPA2B1 to Biotin-MO-460 was also analyzed using a BLItz ${ }^{\mathrm{TM}}$ (Fortebio, Inc., CA, US) instrument with a streptavidin-coated biosensor tip (Pall, USA). The streptavidin-coated tips were pre-wetted for $10 \mathrm{~min}$ in an incubation buffer (10 mM HEPES pH 7.4, 1\% BSA and $0.05 \%$ Tween 20). The streptavidin-coated tips were immobilized with $1 \mu \mathrm{M}$ Biotin-MO-460 in incubation buffer (10 mM HEPES pH 7.4, 1\% BSA and 0.05\% Tween 20) for $5 \mathrm{~min}$. The biosensor was washed with HEPES (pH 7.4) and incubated with 250-, 500- and 1,000$\mathrm{nM}$ concentrations of the full-length and truncated hnRNPA2B1 proteins for $3 \mathrm{~min}$. The concentrations were then incubated with HEPES for another $3 \mathrm{~min}$ to desorb the protein. Analysis of the accurate and precise kinetic constants was performed by the BLItz data analysis software (BLItz Pro 1.1).

\section{Immunofluorescence staining for HIF-1a}

For immunofluorescence observation, Hep3B cells were seeded on microplates at 2 or $5 \times 10^{4}$ cells $/ \mathrm{mL}$ and cultured for $18 \mathrm{~h}$. The cells were further cultured either with or without $200 \mu \mathrm{M} \mathrm{CoCl}$ and simultaneously exposed to various concentrations of MO-460 or siRNAs for $48 \mathrm{~h}$. The medium in the microplate wells was then removed 
and cells were fixed with 3.7\% formaldehyde in PBS for 15 min then permeabilized for 5 min with $100 \%$ cold $\mathrm{MeOH}$. Cells were washed with PBS containing $1 \%$ bovine serum albumin (PBS-1\% BSA), and then treated with $5 \%$ bovine serum albumin for $20 \mathrm{~min}$. The cells in each well were treated with HIF- $1 \alpha$ antibody in PBS- $0.1 \%$ BSA then placed in a humidified atmosphere of $5 \% \mathrm{CO}_{2}$ at $37^{\circ} \mathrm{C}$ and incubated for $60 \mathrm{~min}$. After being washed with PBS-0.1\% BSA, treated wells of HIF- $1 \alpha$ were incubated with Alexa Fluor 488-conjugated mouse anti-IgG antibody in PBS$0.1 \% \mathrm{BSA}$ then incubated at room temperature for $60 \mathrm{~min}$. After being washed with PBS- $0.1 \%$ BSA, the dish wells were overlaid with Hoechst 33342 for 5 min at room temperature and then washed with PBS-0.1\% BSA. Fluorescence was photographed with an inverted ECLIPSE Ti-U microscope (Nikon Corporation, Japan).

\section{RNA extraction and semi-quantitative RT-PCR}

Cells were lysed with TRIzol (Invitrogen) and proteins were extracted with chloroform. RNAs were precipitated with isopropanol and washed with $75 \%$ ethanol diluted with DEPC-treated water. Purity and concentration of RNA was analyzed using nano drop. The cDNA was synthesized from total RNA in a reaction mixture containing $5 \times$ reaction buffer $(250 \mathrm{mM}$ Tris- $\mathrm{HCl} \mathrm{pH} 8.3,375$ $\mathrm{mM} \mathrm{KCl}, 15 \mathrm{mM} \mathrm{MgCl}_{2}, 50 \mathrm{mM}$ DTT), $50 \mu \mathrm{g} / \mathrm{mL}$ Oligo$\mathrm{dT}, 10 \mathrm{mM} \mathrm{dNTP}$, and 50,000 U M-MLV reverse transcriptase (Promega, Madison, WI). Amplified PCR products obtained with $\beta$ actin-specific primers served as internal controls. The sequences of the primers used for this study are listed in Supplementary Materials and Methods 5 and 6.

\section{Purification of hnRNPA2B1 interacting with RNA}

Hep3B cells were cultured at $37{ }^{\circ} \mathrm{C}$ in a $5 \%$ atmospheric concentration of $\mathrm{CO}_{2}$ and $200 \mu \mathrm{M}$ of $\mathrm{CoCl}_{2}$ in the presence or absence of MO-460 $(50 \mu \mathrm{M})$ and the cells harvested after $24 \mathrm{~h}$. Total lysates of Hep3B were prepared in nuclear isolation buffer [128 mM sucrose, $40 \mathrm{mM}$ Tris$\mathrm{HCl} \mathrm{pH} \mathrm{7.5,} 20 \mathrm{mM} \mathrm{MgCl}_{2}, 4 \%$ Triton-X100]. After clarifying by centrifugation at $2500 \times \mathrm{g}$ for $15 \mathrm{~min}$ at $4 .{ }^{\circ} \mathrm{C}$ the nuclear pellet was resuspended in RIP buffer $[150 \mathrm{mM}$ $\mathrm{KCl}, 25 \mathrm{mM}$ Tris- $\mathrm{HCl} \mathrm{pH}$ 7.5, 5 mM EDTA, $0.5 \mathrm{mM}$ DTT, $0.5 \%$ Triton-X100, and protease inhibitor cocktail], and then incubated with $4 \mu \mathrm{g}$ of either control IgG or the antihnRNPA2B1 antibody. After $1.5 \mathrm{~h}$ of incubation, proteinG agarose beads (Santa Cruz Biotechnologies, Santa Cruz, $\mathrm{CA}$ ) were added and then precipitated. RNAs were purified from $90 \%$ of the samples. Eluted RNAs were complemented by reverse transcriptase with random primers. cDNAs were used in the subsequent PCR reactions with the indicated primer sets. The resulting PCR products were separated on a $1.5 \%$ agarose gel. The other $10 \%$ of the samples from which RNA was not collected were separated by SDS-PAGE and then immunoblotted with anti-hnRNPA2B1 antibody.

\section{In vitro translation assay}

HIF-1 $\alpha$ proteins were synthesized using in vitro transcription/translation systems (Promega, Madison, WI), the protocol was followed the manufacturer's instructions. In brief, mixtures containing reaction components were incubated at $30^{\circ} \mathrm{C}$ for $60 \mathrm{~min}$, and then analyzed by Western blotting using HIF-1 $\alpha$. The template was used HIF- $1 \alpha$ plasmid DNA containing untranslated region (Korea human gene bank, Daejeon, Rep. of Korea), and full-length recombinant hnRNPA2B1 and MO-460 were added to the mixture.

\section{Results}

Affinity capture reveals hnRNPA2B1 as target of MO-460

To determine the inhibitory mechanisms of MO-460, we synthesized MO-460 (or biotin-MO-460) (Fig. 1a) as the derivatives of Moracin-O which was reported previously $^{15}$, and note that MO-460 inhibits the accumulation of HIF- $1 \alpha$ protein under cobalt chloride $\left(\mathrm{CoCl}_{2}\right)$ derived mimetic hypoxic conditions in a concentrationdependent manner (Fig. $1 \mathrm{~b}$ and c). For convenience, we used $\mathrm{CoCl}_{2}$ treatment to create hypoxic conditions in subsequent experiments and will refer to this as "mimetic hypoxia," unless stated otherwise.

Next, an affinity capture approach was used to identify MO-460-interacting proteins in the nuclear and cytosolic fractions following the sequential pull-down assay and LC/MS analysis (Supplementary Figure S1a). Several hundred short peptide sequences had matched with various probabilities in protein databases (Supplementary Table S1). Of these, we selected 12 protein candidates with the highest affinities for MO-460 (Table 1 and Supplementary Figure S1b), and inhibited their expression using siRNA to determine their effects on HIF- $1 \alpha$ accumulation in the nuclei under mimetic hypoxia (Fig. 1d and Supplementary Figure S2a). As a result, excluding hnRNPA2B1, a reduction in the expression of the 11 other genes (cytosolic fraction and $\mathrm{NonO}$ in nucleus fraction) did not affect nuclear localization of HIF-1 $\alpha$ when examined by immunofluorescence. On the other hands, knockdown of hnRNPA2B1 led to a reduction of HIF-1 $\alpha$ protein and nuclear localization (Fig. 1e and Supplementary Figure S2b). Interestingly, the depletion of HSP $90 \beta$ by siRNA caused a reduction in the levels of HIF$1 \alpha$ and prominent cell death, however, HIF- $1 \alpha$ protein, like other binding candidates, localized to the nucleus (Supplementary Figure S2c).

To further confirm the observed results, we also knocked down hnRNPA2B1 using lentiviral shRNA. We generated three shRNAs targeting either the coding region (shA2B1 \#1 and \#2) or the 3'-untranslated region 
a

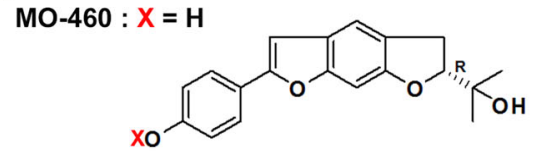

Biotin-MO-460 : $\mathrm{X}=$<smiles>CCCCCCCCCCC1SCC2NC(=O)N[C@@H]21</smiles>

C

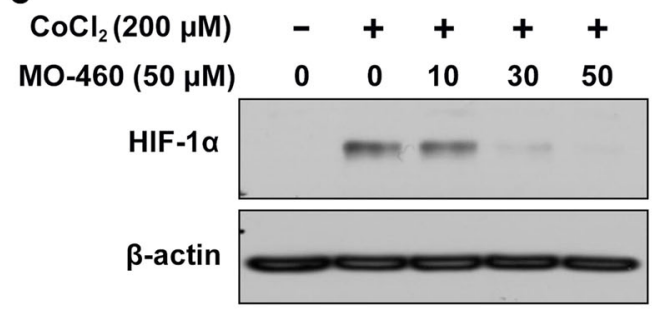

d

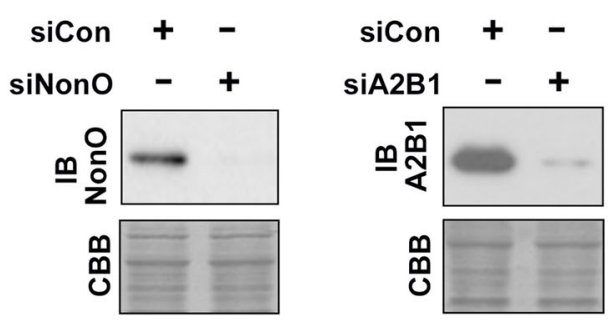

f
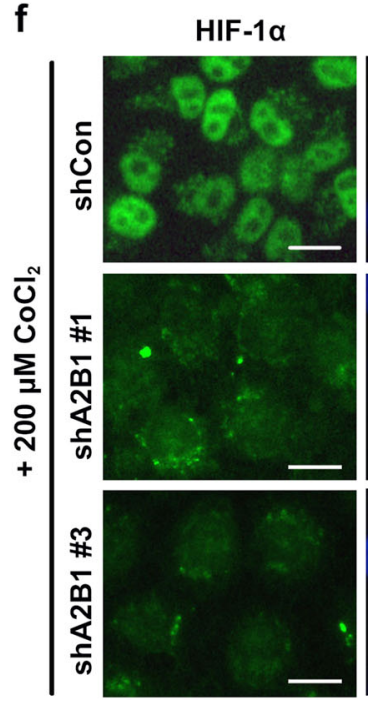

DNA

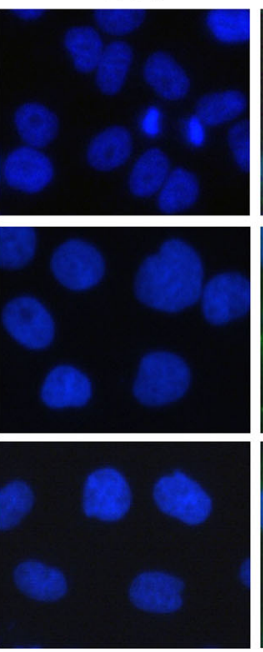

b

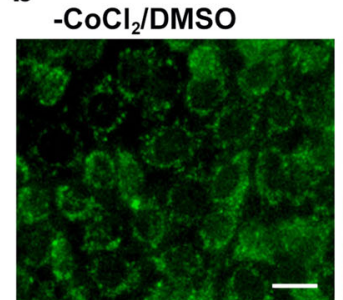

$+\mathrm{CoCl}_{2} / \mathrm{MO}-460(30 \mu \mathrm{M})+\mathrm{CoCl}_{2} / \mathrm{MO}-460(50 \mu \mathrm{M})$

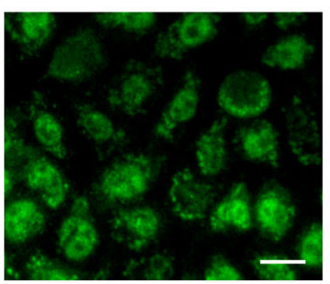

e $-\mathrm{CoCl}_{2} / \mathrm{siCon}$

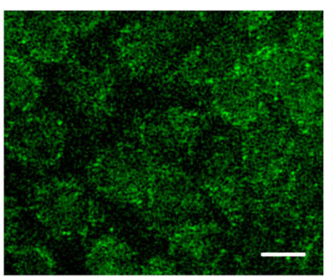

$+\mathrm{CoCl}_{2} /$ siCon
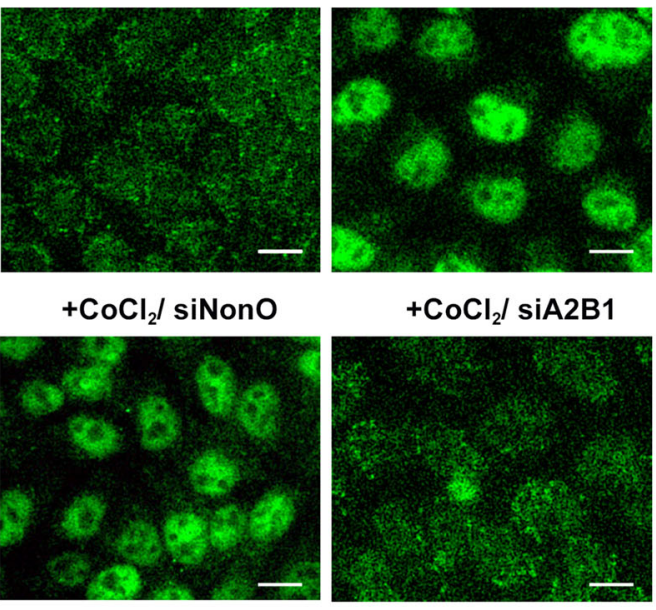

Merge
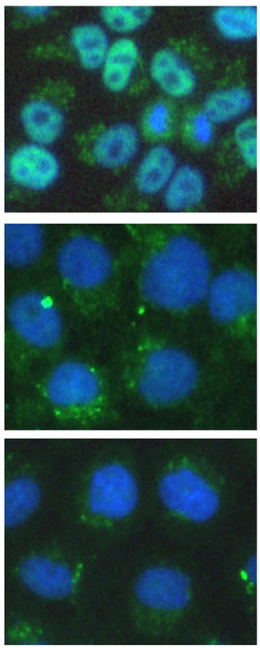

g

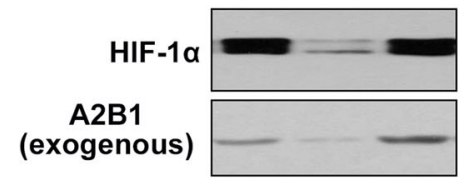

A2B1

(endogenous)

$\beta$-Actin
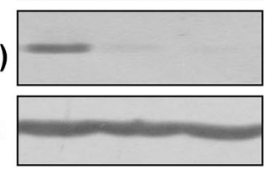

$\mathrm{CoCl}_{2}(200 \mu \mathrm{M})+\quad+\quad+$

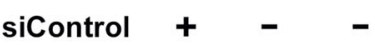

SIA2B1\#1 - +

SIA2B1\#3 - $\quad+\quad+$ 
(see figure on previous page)

Fig. 1 Identification of MO-460-binding proteins. a Structure of MO-460 and its chemical probe (biotin-MO-460). b, c Immunostaining and western blotting of HIF-1a with MO-460 under mimetic hypoxia (Cobalt chloride for $24 \mathrm{~h}$ ). d, e Immunostaining and western blotting of MO-460 binding candidates in nuclear fractions under mimetic hypoxia. Knockdown in each batch of cells was confirmed by western blotting with the indicated antibodies. Equal protein loading was confirmed with Coomassie brilliant blue (CBB) staining; Immunostaining with anti-HIF-1 a antibody. $\mathbf{f}$ Anti-HIF-1a immunostaining of Hep3B cells transduced with shRNAs targeting hnRNPA2B1 (shA2B1\#1 and shA2B1\#3) under mimetic hypoxia. $\mathbf{g}$ Rescue experiments for hnRNPA2B1 on HIF-1a accumulation. Cell lines constitutively expressing a GFP-hnRNPA2B1 fusion protein were treated with either siA2B1\#1 targeting the coding region or SiA2B1\#3 targeting the 3'-untranslated region (UTR) of the hnRNPA2B1 gene. Scale bar, $20 \mu \mathrm{m}$

Table 1 Mo-460 binding candidates from mass spectrometry analysis

\begin{tabular}{llll}
\hline No. & UniPortKB & Protein name (Symbol) & $\begin{array}{l}\text { Seq. coverage by } \\
\text { Mascot report (\%) }\end{array}$ \\
\hline 1 & P04075 & Aldolase A & 39 \\
2 & P04406 & GAPDH & 39 \\
3 & Q15233 & Non-POU Domain Containing, & 38 \\
& & Octamer-Binding (NonO) & \\
4 & P08238 & HSP90 $\beta$ & 38 \\
5 & O75607 & Nucleophosmin 3 (NPM3) & 35 \\
6 & P09651 & hnRNPA1 & 32 \\
7 & P19338 & nucleolin & 34 \\
8 & P22626 & hnRNPA2B1 & 33 \\
9 & Q6PJY1 & DNA helicase V (FUBP1) & 30 \\
10 & P55072 & Valosin-Containing Protein & 23 \\
& & (VCP) & $<20$ \\
11 & Q92841 & DDX17 & hnRNPH1 \\
12 & P31943 & & $<20$ \\
\hline
\end{tabular}

(UTR) (shA2B1 \#3) of hnRNPA2B1 mRNA (Supplementary Figure S2d), and observed inhibition of HIF-1 $\alpha$ when hnRNPA2B1 levels were sufficiently reduced by shA2B1 \#1 or \#3 (Fig. 1f). We further tested if exogenous green fluorescent protein (GFP)-hnRNPA2B1 could compensate for the loss of endogenous hnRNPA2B1 by comparing the effects of siA2B1 \#1 and siA2B1 \#3 on HIF- $1 \alpha$ accumulation. shA2B1 \#1 (targeting the coding region) resulted in a severe reduction in both endogenous hnRNPA2B1 and GFP-hnRNPA2B1, leading to a dramatic reduction in HIF- $1 \alpha$ protein level. In contrast, shA2B1 \#3 (targeting the 3'-UTR) led to a reduction in hnRNPA2B1, but not GFP-hnRNPA2B1, which lacks the 3'-UTR and results in the accumulation of HIF- $1 \alpha$ (Fig. 1g). These data indicate that knockdown of hnRNPA2B1 can be complemented by exogenous hnRNPA2B1, and suggest that hnRNPA2B1 is necessary for the accumulation of HIF-1 $\alpha$.

We then confirmed that real hypoxia (ie, a $1 \%$ oxygen concentration) caused an accumulation of HIF- $1 \alpha$, similar to that observed with $\mathrm{CoCl}_{2}$ treatment. Under real hypoxia, (R)-(-)-moracin O treatment, MO-460 treatment, and hnRNPA2B1 knockdown led to a reduction in HIF- $1 \alpha$ accumulation (Supplementary Figure S3). These findings demonstrate for the first time that hnRNPA2B1 plays an important role in HIF- $1 \alpha$ accumulation under mimetic hypoxia and that MO-460 can efficiently inhibit HIF-1 $\alpha$ expression through hnRNPA2B1.

\section{MO-460 directly binds to the C-terminus of hnRNPA2B1}

Because hnRNPA2B1 in cell lysates was captured by affinity to MO-460 (Supplementary Figure S1), it was necessary to determine whether MO-460 binds directly to hnRNPA2B1. To perform pull-down assays, purified hnRNPA2B1 recombinant proteins were co-precipitated with biotin-MO-460. The interaction between hnRNPA2B1 and the biotin-MO-460 was eliminated by adding an excess amount of MO-460 to the assay mixture (Fig. 2a). These results suggest direct interactions between MO-460 and hnRNPA2B1.

We further established the MO-460 binding region on hnRNPA2B1 using stable cell lines that express domainbased constructs of hnRNPA2B1 fused to GFP (Fig. 2b, upper panel). In pull-down assays, both the full-length hnRNPA2B1 and the C-terminal glycine-rich domain (GRD) strongly bound to biotin-MO-460. However, the RNA recognition motifs RRM1, RRM2, and RRM1-RRM2 in the N-terminal half of the protein did not bind to biotin-MO-460 (Fig. 2c). Next, we measured MO-460 binding affinity to hnRNPA2B1 using the BLITz association-dissociation assay system. Purified bacterial recombinant proteins (Fig. 2b, bottom panel, and Supplementary Figure S4a) were attached to biotin-MO-460, and evaluated dissociation constants (Kd). The full-length hnRNPA2B1 and GRD clearly bound to biotin-MO-460 with apparent $\mathrm{Kd}$ of $1.14 \times 10^{-5} \mathrm{M}$ and $6.6 \times 10^{-6} \mathrm{M}$, respectively, and the RRM of hnRNPA2B1 showed no specific interactions (Fig. $2 \mathrm{~d}$ and Table 2 upper panel). Together, these experiments reveal that the C-terminal GRD of hnRNPA2B1 is critical for MO-460 activity.

To determine the binding site within the GRD, we designed five constructs that expressed $~ 50$-amino-acidlong oligopeptides representing different regions within the GRD domain fused to glutathione-S-transferase (GST) (Fig. 2b, bottom panel, and Supplementary Figure S4b). As 

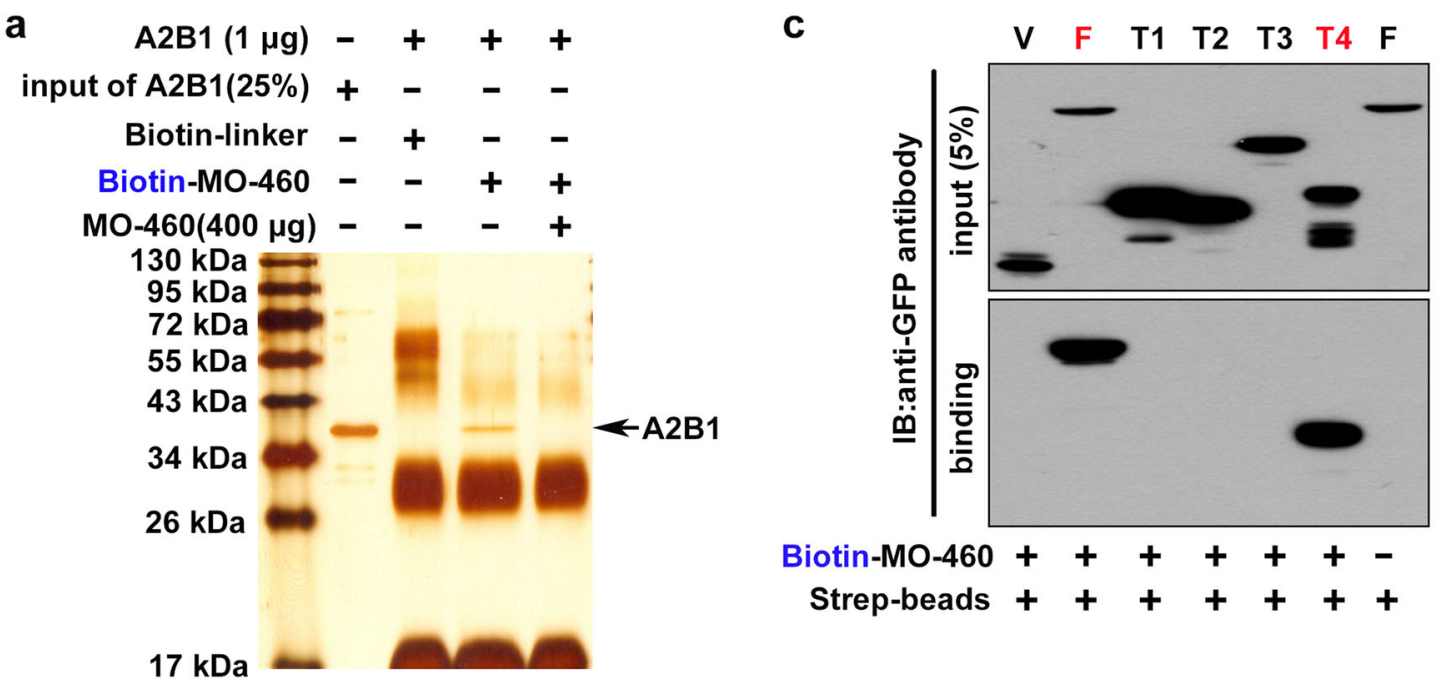

b

mammalian exp.

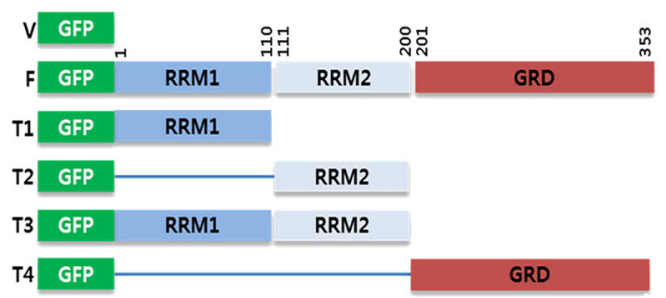

d

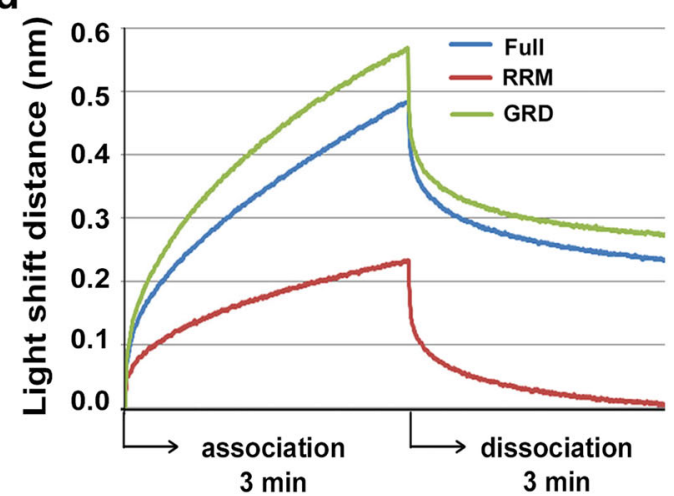

\section{bacterial exp.}
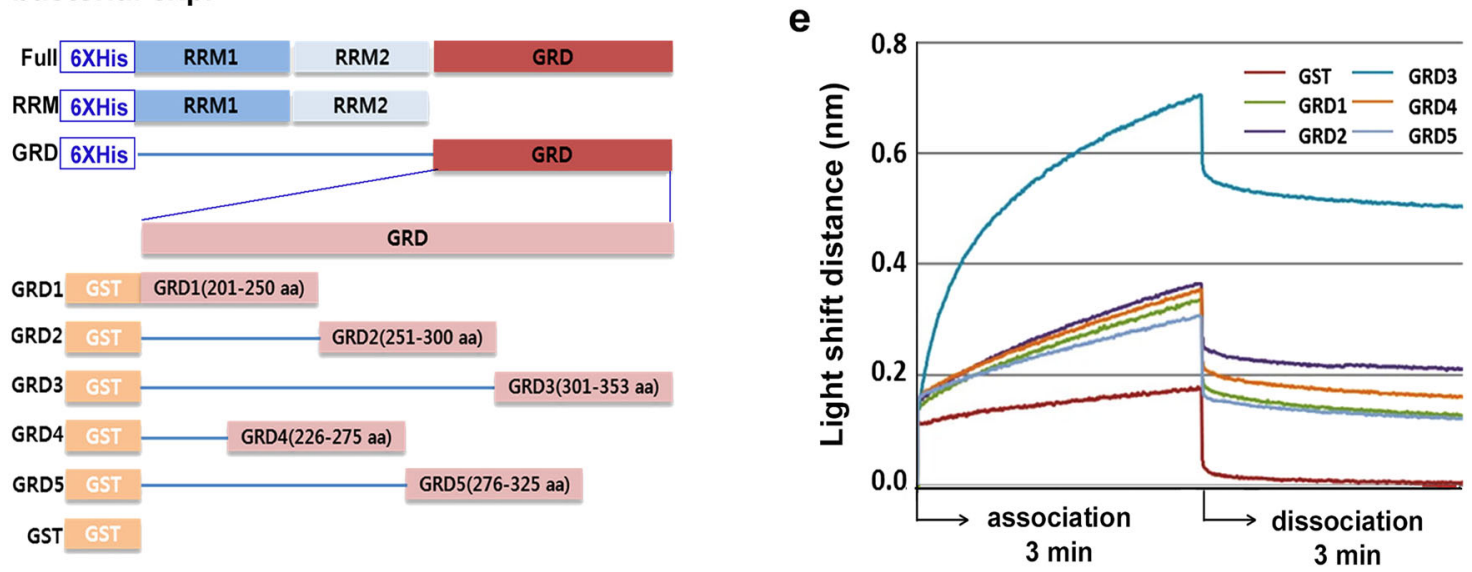

Fig. 2 Direct interactions between MO-460 and hnRNPA2B1. a Pull-down assay of hnRNPA2B1 protein with biotin-MO-460 or in the presence of excess amounts of MO-460. b Schematic of hnRNPA2B1 protein construction variants. $\mathbf{c}$ Western blotting of GFP pull-down assay from cells transfected with varying constructs following incubation with streptavidin-conjugated biotinylated MO-460 (Biotin-MO-460); immunoblotting with anti-GFP antibody. $\mathbf{d}$, e Kd values of MO-460 with three domain-dependent hnRNPA2B1 constructs and GRD domain constructs. Measurements were made with the BLITz system under sequential association and dissociation conditions. Binding affinity was measured every second for 3 min

shown in the lower panel of Table 2, the Kd value between MO-460 and GRD3 was $\sim 2.99 \times 10^{-7} \mathrm{M}$ (greater than $10^{4}$ times lower than that of the other GRDs under the same conditions). Specifically, only GRD3 containing 28 amino acids (amino acids 326-353) at the C-terminus strongly interacted with MO-460 (Fig. 2e and Table 2 bottom panel). The results of all assays consistently suggested that the two molecules interacted, indicating that MO-460 
Table 2 Binding affinities of MO-460 to the hnRNPA2B1 GRD region

\begin{tabular}{llllll}
\hline hnRNPA2B1 GRD domain & Region (amino acid) & Con. (uM) & Kd (M) & Standard deviation (M) & Standard error (M) \\
\hline Full* & $1-353$ aa & 5 & $1.14 \times 10^{-5}$ & $\pm 1.57 \times 10^{-6}$ & $\pm 1.11 \times 10^{-6}$ \\
RRM $^{*}$ & $1-193$ aa & 5 & $1.36 \times 10^{-2}$ & $\pm 4.21 \times 10^{-3}$ & $\pm 2.98 \times 10^{-3}$ \\
GRD* & $202-353$ aa & 5 & $6.60 \times 10^{-6}$ & $\pm 2.15 \times 10^{-6}$ & $\pm 1.52 \times 10^{-6}$ \\
GST & - & 5 & $5.00 \times 10^{-3}$ & $\pm 4.21 \times 10^{-4}$ & $\pm 2.10 \times 10^{-4}$ \\
GRD1 & $201-250$ aa & 5 & $3.05 \times 10^{-3}$ & $\pm 2.15 \times 10^{-3}$ & $\pm 1.07 \times 10^{-3}$ \\
GRD2 & $251-300$ aa & 5 & $3.67 \times 10^{-3}$ & $\pm 2.78 \times 10^{-3}$ & $\pm 1.39 \times 10^{-3}$ \\
GRD3 & $301-353$ aa & 5 & $2.99 \times 10^{-7}$ & $\pm 2.67 \times 10^{-7}$ & $\pm 1.34 \times 10^{-7}$ \\
GRD4 & $226-275$ aa & 5 & $3.48 \times 10^{-3}$ & $\pm 4.11 \times 10^{-3}$ & $\pm 2.05 \times 10^{-3}$ \\
GRD5 & $276-325$ aa & 5 & $3.35 \times 10^{-3}$ & $\pm 5.02 \times 10^{-3}$ & $\pm 2.51 \times 10^{-3}$ \\
\hline
\end{tabular}

* 6XHis tagged protein

directly binds to hnRNPA2B1 through interaction with amino acids $326-353$ in the C-terminal region.

\section{MO-460 does not affect HIF-1a transcriptional regulation}

We evaluated the possibility that binding of MO-460 to hnRNPA2B1 regulates hypoxia-induced HIF-1 $\alpha$ expression at the transcriptional level. As shown in Fig. 3a, treatment of Hep3B cells with $50 \mu \mathrm{M}$ of MO-460 caused a marginal reduction $(\sim 10 \%)$ in $H I F-1 \alpha$ mRNA level as detected with qRT-PCR. Treatment of MO-460 under normoxic condition had no observed effect (Supplementary Figure S5). In support of this result, knockdown of hnRNPA2B1 by siA2B1 also resulted in only a slight reduction in $H I F-1 \alpha$ mRNA level. This slight reduction cannot account for the nearly complete elimination of HIF- $1 \alpha$ proteins (Fig. 3a), suggesting posttranscriptional or translational control of HIF-1 $\alpha$ expression by hnRNPA2B1 in response to MO-460.

MO-460 reduced the level of HIF-1 $\alpha$ protein in a concentration-dependent manner with no effect on the amount of hnRNPA2B1. Exogenous overexpression of HA-hnRNPB1, however, induced a notable reversal of the inhibitory effect of MO-460 on HIF- $1 \alpha$ accumulation, as revealed by western blot analysis (Fig. $3 b$ ). This indicates that the reduction in HIF-1 $\alpha$ expression by MO-460 can be partially reversed by transient overexpression of hnRNPA2B1.

MO-460 inhibits interaction between hnRNPA2B1 and the 3'UTR of HIF-1a mRNA

hnRNPA2B1 is an RNA-binding protein that binds to and regulates the stability or translation of target mRNAs ${ }^{17,29}$, and some RNA binding proteins are related to the regulation of $H I F-1 \alpha$ mRNA turnover and translation $^{30,31}$. To determine if hnRNPA2B1 binds to HIF-1 $\alpha$ mRNA, we performed an RNA-immunoprecipitation assay. These result show that hnRNPA2B1 interacts with HIF-1 $\alpha$ mRNA in Hep3B cell lysates or GFPhnRNPA2B1 overexpression cell lysates (Supplementary Figure S7). However, there appears to be no direct interaction between HIF-1 $\alpha$ protein and hnRNPA2B1, and MO-460 did not bind to HIF-1 $\alpha$ protein in two rounds of the affinity capture experiment (Supplementary Figure S7 and Supplementary Table S1). Thus, these data suggest that hnRNPA2B1 binds to HIF-1 $\alpha$ mRNA, not HIF-1 $\alpha$ protein.

To further investigate the mechanism of HIF- $1 \alpha$ reduction by $\mathrm{MO}-460$ treatment, we explored the interaction between hnRNPA2B1 and HIF-1 $\alpha$ mRNA under in presence of MO-460. The hnRNPA2B1 protein and HIF$1 \alpha$ mRNA complex was immunoprecipitated from whole lysates of Hep3B cells cultured under mimetic hypoxia. But, this interaction was abolished in presence of MO460. In addition, there was no detectable $H I F-1 \beta$ mRNA regardless of MO-460 treatment (Fig. 4a). This result suggests that hnRNPA2B1 binds to $H I F-1 \alpha$ mRNA under mimetic hypoxia and that MO-460 inhibits their interaction.

And we further tested whether which region of $H I F-1 \alpha$ mRNA is important for hnRNPA2B1 binding, Hep3B cells were transiently transfected with several luciferaseexpression constructs possessing 5'-, 3'-, or both UTR regions of $H I F-1 \alpha$ (Fig. 4b). An anti-hnRNPA2B1 antibody preferentially precipitated luciferase mRNA with the HIF-1 $\alpha$ 3'-UTR (Fig. 4c). Similarly, luciferase activity was significantly reduced in hnRNPA2B1-depleted cells expressing luciferase constructs with the HIF-1 $\alpha$ 3'-UTR (Fig. 4d). These results suggest that the 3'-UTR of the $H I F-1 \alpha$ transcript is important for hnRNPA2B1 binding and regulation.

\section{hnRNPA2B1 is required for HIF-1a protein synthesis}

HIF- $1 \alpha$ undergoes hydroxylation at proline residues 402 and 564 and is ubiquitinated and subsequently targeted 

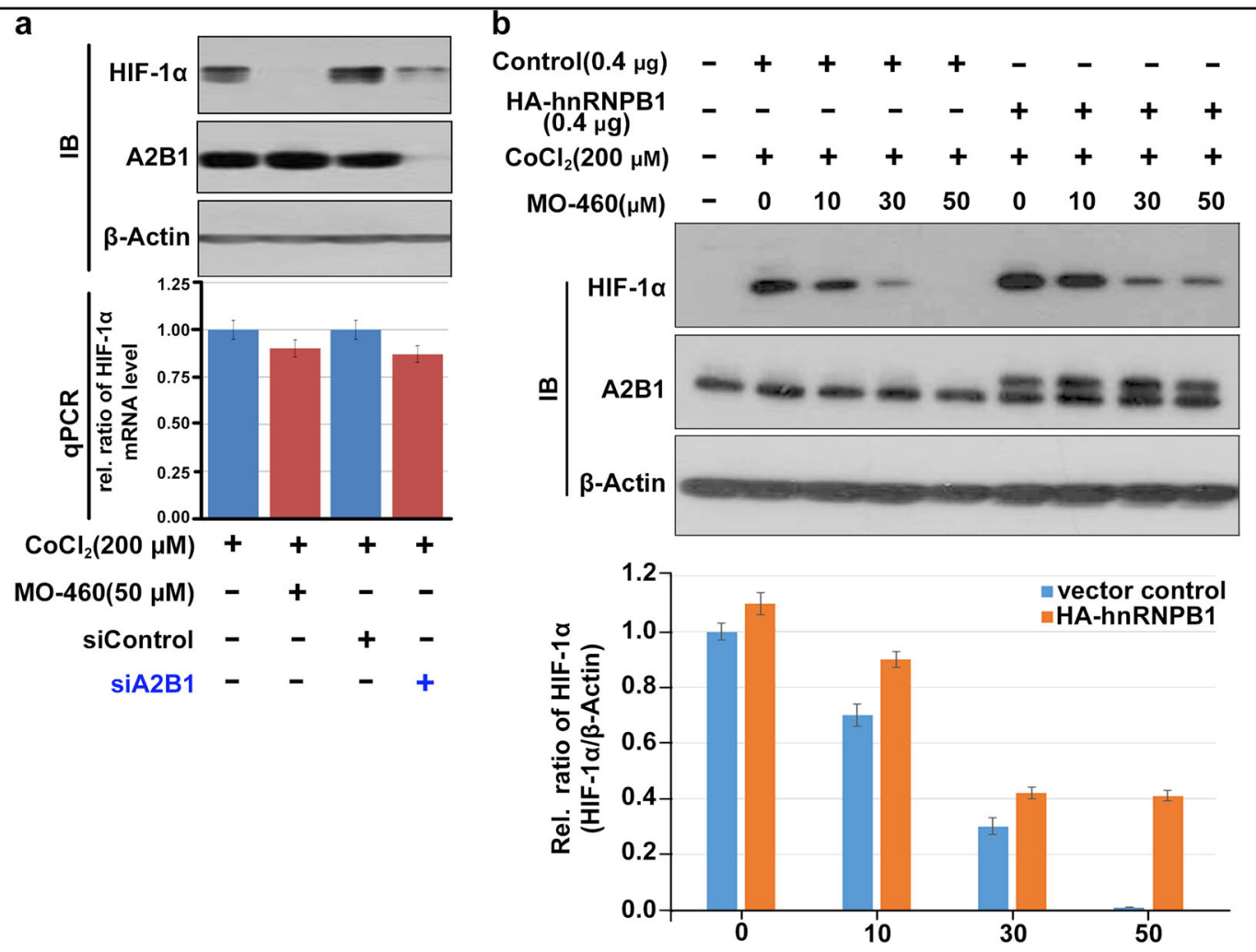

Fig. 3 Interactions between MO-460, hnRNPA2B1, and HIF-1a. a Western blotting and qRT-PCR of HIF-1a were performed in Hep3B cells treated with MO-460 or hnRNPA2B1 siRNA under mimetic hypoxia. b Western blotting of HIF-1a was examined on MO-460 treatment in presence or absence of exogenous hnRNPA2B1. Data presented as the mean \pm SD of three experiments

for proteasomal degradation under normoxic conditions $^{32}$. To examine whether MO-460-mediated inhibition of HIF- $1 \alpha$ accumulation was due to increased protein degradation, 2 missense mutations (P402A, P564A) were introduced into HIF- $1 \alpha$ to prevent its ubiquitindependent degradation. Both wild-type and mutant HIF$1 \alpha$ proteins accumulated in the presence of hnRNPA2B1, but their levels were reduced in its absence under mimetic hypoxia (Fig. 5a). In the absence of hnRNPA2B1, the reduction was similar between wild-type and mutant HIF$1 \alpha$, suggesting that protein degradation is not the primary mechanism of hnRNPA2B1 or MO-460-mediated regulation of HIF- $1 \alpha$ protein levels.

Previous experiments investigating transcription suppression and protein degradation suggest that neither of these were the core pathway for the reduced accumulation of HIF- $1 \alpha$ by MO-460 treatment or inhibition of its binding partner, hnRNPA2B1. Accumulation of HIF-1 $\alpha$, however, may be related to protein synthesis. We evaluated the effects of hnRNPA2B1 on HIF-1 $\alpha$ protein synthesis under mimetic hypoxia. Cells were incubated with cycloheximide (CHX) for $4 \mathrm{~h}$ before addition of $\mathrm{CoCl}_{2}$ to prevent de novo protein synthesis, and then levels of newly synthesized protein were observed for up to $4 \mathrm{~h}$ (Fig. $5 \mathrm{~b}$ ). Under mimetic hypoxia, newly synthesized HIF- $1 \alpha$ protein expression was diminished in the absence of hnRNPA2B1 (Fig. 5c). And, to verify the relationship between hnRNPA2B1 and MO-460 in HIF$1 \alpha$ protein translation, we performed an in vitro translation assay. Purified hnRNPA2B1 protein more enhanced HIF- $1 \alpha$ translation than HIF- $1 \alpha$ only, but MO-460 treatment attenuated this effect (Fig. 5d). These results strongly suggest that hnRNPA2B1 augments the translation of HIF-1 $\alpha$. In addition, the hnRNPA2B1-targeting small molecule, MO-460, can interfere with this process.

MO-460 induces accumulation of stress granules (SGs) by regulating hnRNPA2B1

Both MO-460 treatment and hnRNPA2B1-inhibition appear to impede HIF- $1 \alpha$ translation. In mammalian cells, cytotoxic stress triggers several signaling cascades that converge on stress granules, shuttling nuclear RNAbinding proteins such as T-cell intracellular antigen-1 (TIA-1) to the cytoplasm, and aggregating cellular mRNAs into TIA-1-containing complex, thus protein synthesis is greatly impaired ${ }^{33}$. To test whether hnRNPA2B1 was involved in stress granulation formation, sodium arsenite as a stress-inducing agent was 


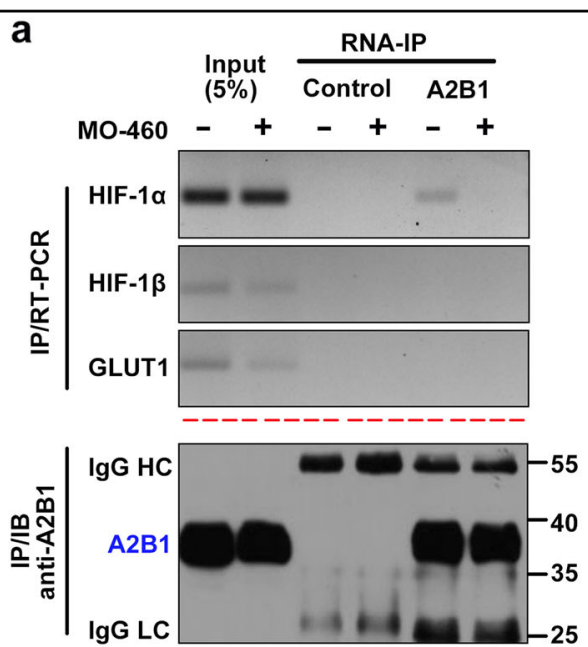

C

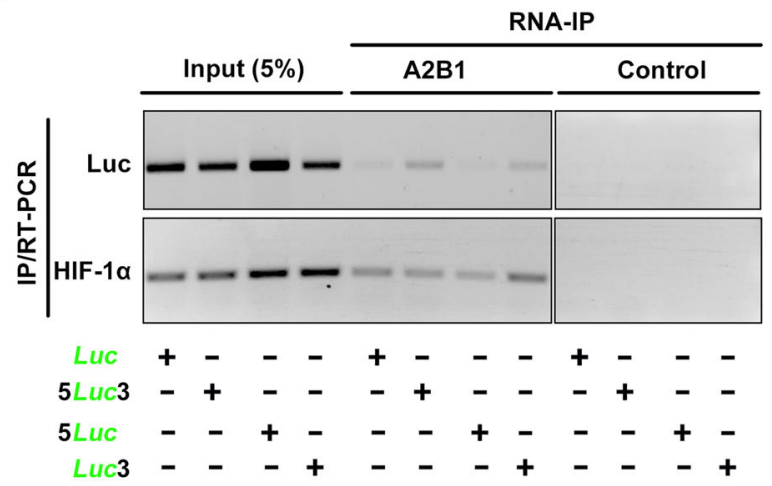

b

5'UTR-HIF1 $\alpha-3$ 'UTR

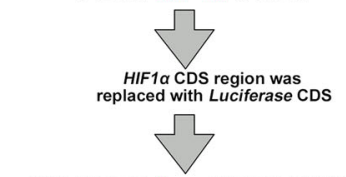

pCM-5'UTR-LUC-3'UTR-SV40 poly A

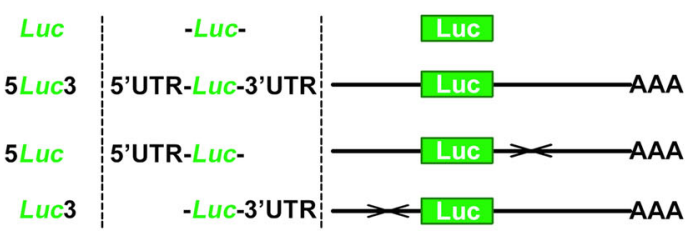

d

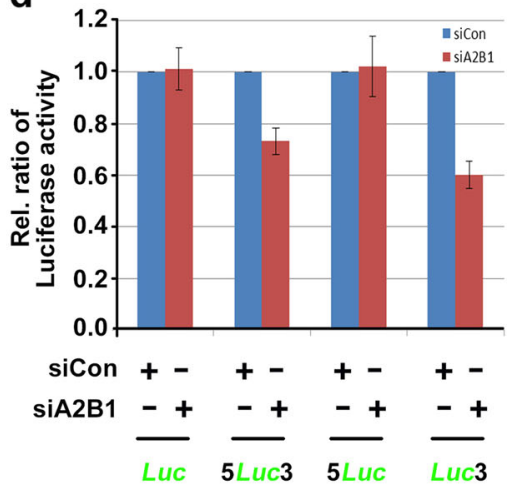

Fig. 4 Inhibitory effect of MO-460 mediated by direct interaction of hnRNPA2B1 with the 3'-UTR of HIF-1a mRNA. a Effect of MO-460 on RNA-immunoprecipitation with hnRNPA2B1 and HIF-1a mRNA. HIF-1 $\beta$ and GLUT1 are used to negative controls. $\mathbf{b}$ Schematic of luciferase gene constructs flanked by untranslated regions of the HIF-1a transcript. c RNA-immunoprecipitation of hnRNPA2B1 with the untranslated region (UTR)based luciferase constructs. Relative transcript levels of endogenous HIF-1a and exogenous luciferase genes were examined by RT-PCR. $\mathbf{d}$ UTR reporter assay was measured by luciferase enzyme activity in the cells transfected with each chimeric construct. Data presented as the mean \pm SD of three experiments

treated with GFP and GFP-hnRNPA2B1 expressing cell lines. Unlike GFP, GFP-hnRNPA2B1 co-localized with TIA-1 (Supplementary Figure S8). And treatment with MO-460 causes formation of cytoplasmic dots in hnRNPA2B1 and it is co-localized with TIA-1, even the expression levels of hnRNPA2B1 and TIA-1 proteins were not altered (Fig. 6a and b). These data imply that MO-460 relates to the regulation of HIF- $1 \alpha$ protein synthesis by regulating hnRNPA2B1 via stress granules.

\section{Discussion}

Cancer cells systematically change their transcriptome and subsequently their proteome in response to hypoxic challenges caused by rapid cell proliferation. These responses include adaptive mechanisms such as survival, division, motility, and cell differentiation ${ }^{2,3}$. Most of these transcriptional changes are orchestrated by the key regulatory transcription factor, HIF-1, which is also responsible for the resistance of cancer cells to chemotherapy ${ }^{9,34,35}$. HIF-1 is a heterodimer consisting of two HIF-1 subunits, alpha and beta. HIF- $1 \alpha$ responds to and accumulates under hypoxic conditions, in contrast to constitutively expressed HIF- $1 \beta$. Thus, HIF- $1 \alpha$ has become an important therapeutic target for solid tumors. The roles of numerous small molecules used to treat various cancers by inhibiting HIF- $1 \alpha$ activity have been characterized. However, additional compounds with verified mechanisms of action are expected to be developed as drugs for either single or combination therapies ${ }^{32}$.

Previous research has shown that the natural compound (R)-(-)-moracin-O suppress HIF- $1 \alpha$ nuclear accumulation under hypoxic conditions, but the mechanism remained unclear $^{16}$. To our knowledge, the current study is the first to identify and characterize the mechanism of HIF- $1 \alpha$ suppression by MO-460. First, we identified that 


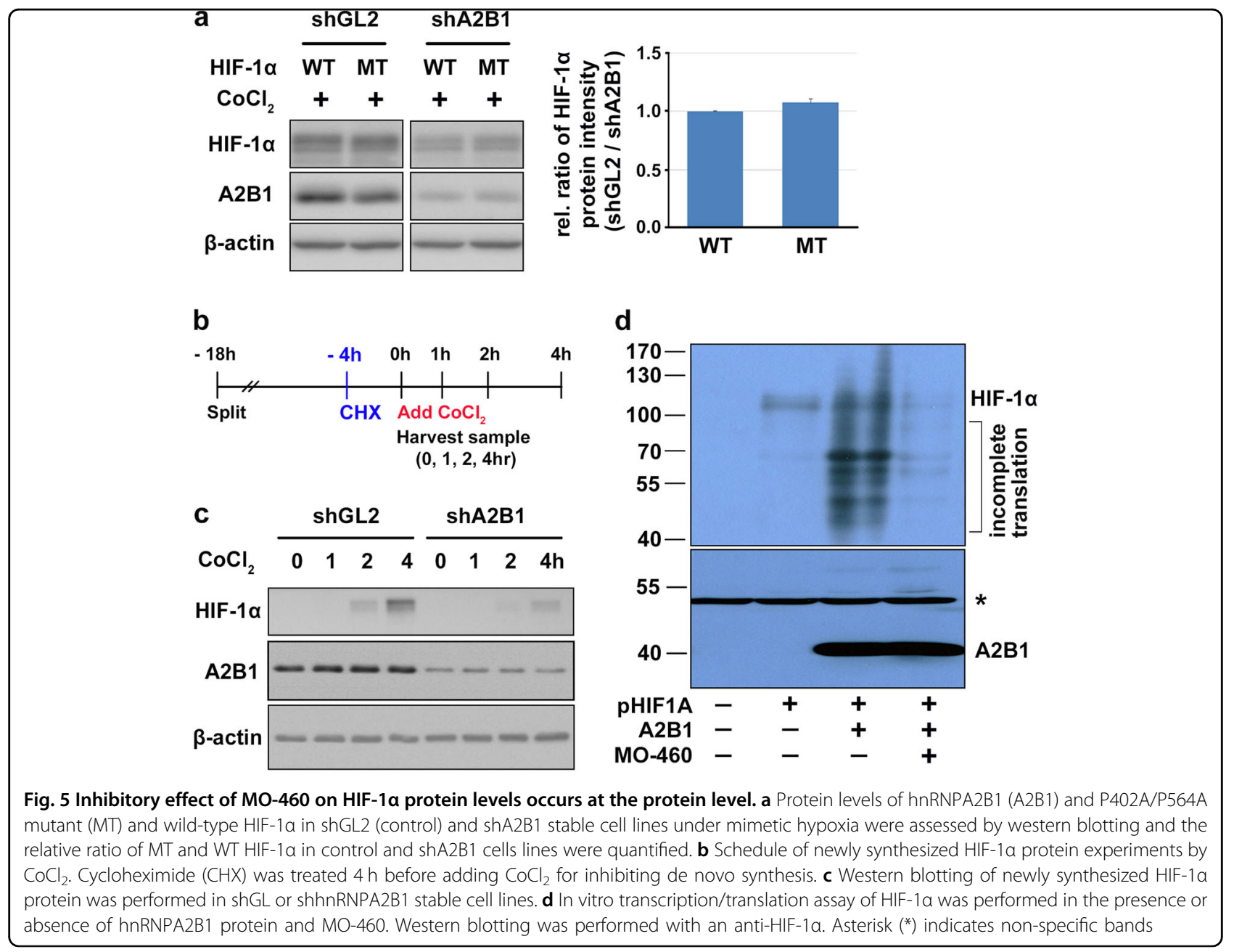

hnRNPA2B1 is a binding target of MO-460. hnRNPA2B1 is not only a biomarker for cancers, but also an oncogene that regulates tumor suppressors and other oncogenes in various cancers ${ }^{27,36}$. hnRNPA2B1 is overexpressed in cancer cell lines derived from many organs including the lung, breast, gastrointestinal tract, brain, cervix, and ovary $^{37-39}$. Overexpression of hnRNPA2B1 is wellestablished as a biomarker for the early stages of nonsmall cell lung cancers, epithelial transformation, and carcinogenesis ${ }^{40}$. It also plays essential roles in carcinogenesis and the progression of cancer with respect to fundamental biological functions (e.g., glucose metabo$\operatorname{lism}^{41}$, cell cycle $^{42}$, cell proliferation ${ }^{43}$, invasive migra$\left.\operatorname{tion}^{18}\right)$. Specifically, its role in cell proliferation was supported by the observation that siRNA-mediated reduction of hnRNPA2B1 levels provoked rapid cell death by apoptosis in cell lines derived from diverse cancers of the cervix, colon, breast, ovary, and brain, but not in noncancerous fibroblastic or epithelial cell lines ${ }^{38}$. The results indicate that hnRNPA2B1 may provide a target for the treatment of a variety of cancers. Especially, the 28 amino acids in the C-terminal end of hnRNPA2B1 (GRD3) showed higher binding affinity than the fulllength protein (Fig. 2 and Table 2). These binding affinity results suggest a strong physical interaction, which is a desirable property in potential drug candidates.

Second, we characterized the interaction between hnRNPA2B1 and 3'-UTR of HIF-1 $\alpha$ mRNA and regulation of hnRNPA2B1 to HIF-1 $\alpha$. The hnRNPA2B1 protein belongs to a family of RNA-binding proteins with more than 20 members, which are abundantly expressed in most human tissues and play diverse roles in the posttranscriptional processing of mRNA and its subsequent packaging, transport, and translation ${ }^{17}$. According to previous studies, hnRNPA2B1 enhances cap-dependent translation without affecting internal ribosome entry sitedependent translation for transcripts containing RNA trafficking signals ${ }^{19}$. hnRNPA2, isoform of hnRNPA2B1 decreases the stability and translation of GLUT1 by binding to the 3'-UTR under normoxia and de-represses translation by selectively inhibiting this interaction under hypoxic conditions ${ }^{23}$, and it acts as a regulator in the RNA 


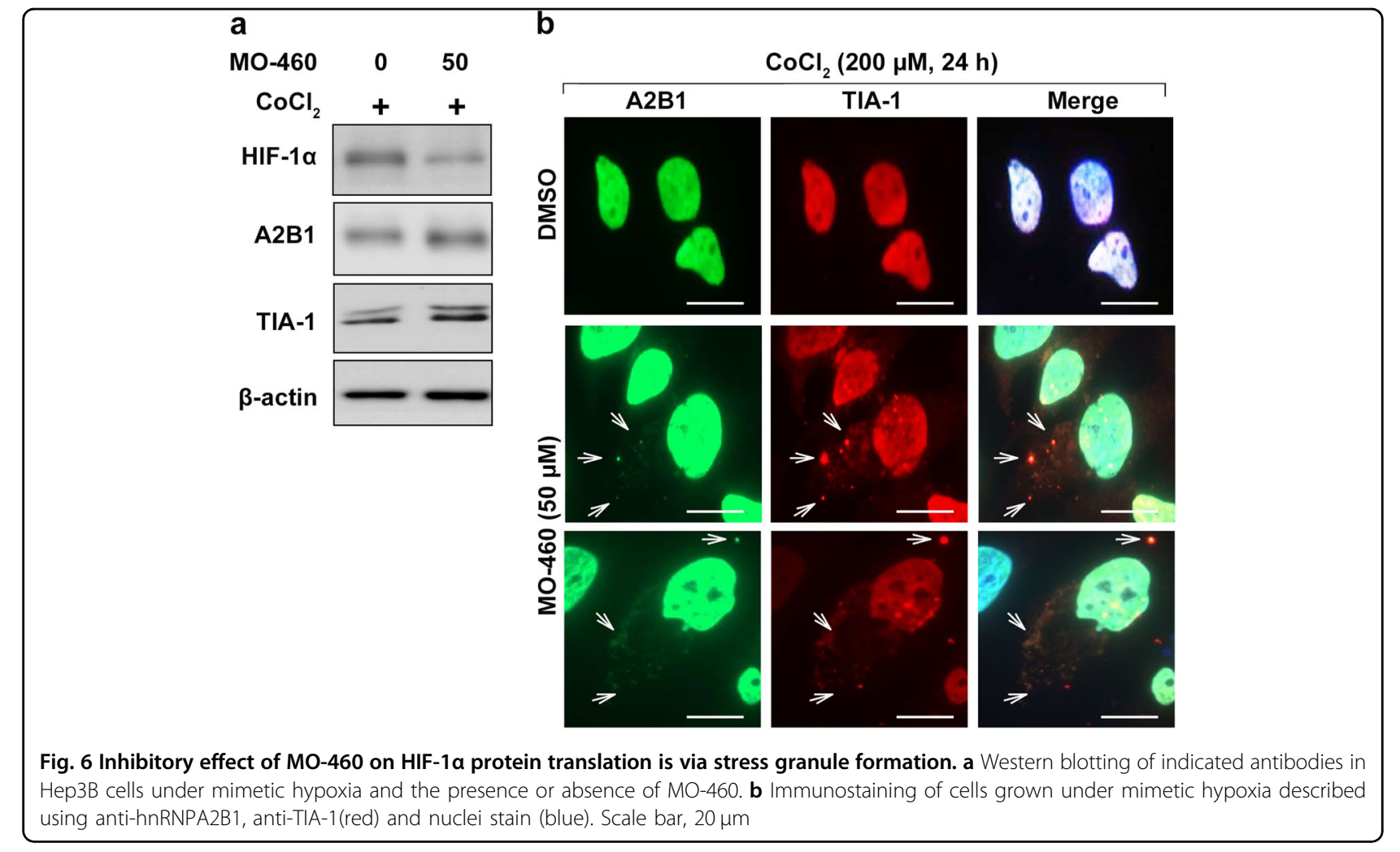

b

splicing process and a natural compound, apigenin, inhibits its splicing activity ${ }^{44}$. However, the MO-460 target, hnRNPA2B1, has little effect in the case of $H I F-1 \alpha$ RNA processing (Supplementary Figure S6).

Similar to other RNA-binding proteins, hnRNPA2B1 binds to $H I F-1 \alpha$ transcripts (Fig. 4a) and has no direct interaction with the HIF-1 $\alpha$ protein (Supplementary Figure S7). Moreover, hnRNPA2B1 binds specifically to HIF$1 \alpha$ mRNA, and not to other HIF-related transcripts such as $H I F-2 \alpha, H I F-3 \alpha$, and $H I F-1 \beta$. Suppression of hnRNPA2B1 function by siRNA, shRNA, or MO-460 treatment resulted in the failure of HIF-1 $\alpha$ protein accumulation under hypoxic conditions but had little effect $(<10 \%)$ on HIF-1 $\alpha$ transcript levels (Fig. 3a). This reduction is not sufficient to explain the large decrease in HIF$1 \alpha$ protein levels. In addition, even in normoxic conditions, MO-460 treatment did not affect HIF-1 $\alpha$ transcript levels (Supplementary Figure S5a). These results suggest that hnRNPA2B1 has mainly impacts post-transcriptional or translational regulation rather than the transcription.

hnRNPA2B1 plays an important role in the accumulation of HIF-1 $\alpha$ in Hep3B liver cancer cells under mimetic hypoxia. Our RNA immunoprecipitation experiments showed that hnRNPA2B1 preferentially binds the 3'-UTR of HIF-1 $\alpha$ mRNA, although the quantity of luciferase transcripts expressed from each construct was similar (Fig. 4c), probably due to the strong CMV promoter activity (Fig. 4b). The luciferase transcription levels from each construct were similar regardless of hnRNPA2B1 depletion in the cells in the absence of the HIF-1 $\alpha$ 3'-UTR. In the presence of the HIF-1 $\alpha$ 3'-UTR, however, the luciferase activity decreased by $20-40 \%$ when hnRNPA2B1 was knocked down (Fig. 4d). The results obtained from the RNA binding and UTR reporter assays suggest that hnRNPA2B1 binds to the 3'-UTR of HIF-1 $\alpha$ mRNA, enhancing HIF-1 $\alpha$ protein expression.

Third, accumulation of HIF-1 $\alpha$ protein in cells under hypoxic conditions may be related to an inhibition in degradation or an increase in protein synthesis ${ }^{2}$. Under normoxia, HIF-1 $\alpha$ protein is rapidly ubiquitinated by the von Hippel Lindau protein (pVHL) complex and subsequently targeted for proteasomal degradation ${ }^{45}$. MO-460 treatment under hypoxic conditions completely eliminated the accumulation of HIF-1 $\alpha$ (Fig. 1 and Supplementary Figure S3). Wild-type and degradation-defective (MT) HIF-1 $\alpha$ exhibited little difference in nuclear accumulation or degradation under mimetic hypoxia in the presence or absence of hnRNPA2B1 (Fig. 5a). We excluded the possibility that the lack of HIF- $1 \alpha$ accumulation after MO-460 treatment or hnRNPA2B1 knockdown was due to increased protein degradation. Finally, we found that treatment with MO-460 or hnRNPA2B1 depletion under hypoxic conditions decreased HIF-1 $\alpha$ protein translation (Fig. 5). 
Then, we investigated how protein synthesis is affected by MO-460 treatment or hnRNPA2B1 inhibition. A recent study reported that a mutation in hnRNPA2B1 promotes the formation of stress granules associated with RNAs $^{46,47}$. The formation of stress granules is an inhibitory process for protein synthesis ${ }^{48,49}$. Here, we observed that hnRNPA2B1 colocalized with TIA-1, a stress granule marker, with sodium arsenite treatment, a known stress granule inducer (Supplementary Figure S8). Thus, we confirmed stress granule formation in response to $\mathrm{MO}$ 460 treatment (Fig. 6). These results suggest that MO-460 treatment might be caused inhibition of HIF- $1 \alpha$ protein synthesis via stress granules mediated by hnRNPA2B1.

Although it is premature to discuss the extent of MO460 targets, it is possible that the functions of the 11 selected MO-460 binding proteins (Supplementary Figure S2) could also be affected by MO-460 binding. Functional inhibition of any of these proteins would exert a considerable effect on carcinogenesis, angiogenesis, and metastasis considering the roles of nucleolin, for example, in angiogenesis and tumor development ${ }^{50,51}$ and of nucleophosmin in the ARF-p53 tumor suppressor pathway ${ }^{52}$. However, from our results, among MO-460 targets, hnRNPA2B1 seems to be valuable as an anti-cancer target on HIF-1 $\alpha$ inhibition. Functional suppression of hnRNPA2B1 inhibits alternative splicing of pyruvate kinase muscle isozyme M2 (PKM2), a key enzyme for glucose metabolism in tumors ${ }^{41}$, and tumor protein P53 inducible nuclear protein2 (TP53INP2), an important component of invasive cell movement ${ }^{18}$. Moreover, (R)(-)-moracin-O and its synthetic derivative, MO-460, bind to hnRNPA2B1 (Figs. 1 and 2) and suppress HIF-1 $\alpha$ nuclear accumulation though inhibition of protein synthesis under hypoxic conditions. This benzofuranbased small molecule, MO-460, warrants further exploration as a drug candidate for the development of novel anticancer therapeutics.

\section{Acknowledgements}

This work was supported by the National Research Council of Science \& Technology (NST) grant (CAP-16-03-KRIBB and ASIA-16-011), the National Research Foundation of Korea (NRF) grant (NRF-2016R1A2B3011389 and NRF2018R1A5A2023127), and KRIBB Research Initiative Program funded by the Ministry of Science and ICT, Korea. And we highly thank Mr. Michel Molstad for kindly proofreading the manuscripts.

\footnotetext{
Author details

${ }^{1}$ Anticancer Agent Research Center, Korea Research Institute of Bioscience and Biotechnology, Cheongju 28116, Korea. ${ }^{2}$ Department of Biomolecular Science, University of Science and Technology, Daejeon 34113, Korea. ${ }^{3} \mathrm{Chemical}$ Biology Research Group, RIKEN CSRS, Wako, Saitama 351-0198, Japan. ${ }^{4}$ College of Pharmacy, Dongguk University, Goyang 10326, Korea. ${ }^{5}$ Protein Metabolism Medical Research Center, Department of Biomedical Sciences, College of Medicine, Seoul National University, Seoul 03080, Korea. 'ab of Metabolism, National Cancer Institute, National Institutes of Health, Bethesda, MD 20892, USA. ${ }^{7}$ Present address: Kitasato Institute for Life Sciences, Kitasato University, 59-1 Shirokane, Minato Ku, Tokyo 108-8641, Japan
}

Conflict of interest

The authors declare that they have no conflict of interest.

\section{Publisher's note}

Springer Nature remains neutral with regard to jurisdictional claims in published maps and institutional affiliations.

Supplementary information accompanies this paper at https://doi.org/ 10.1038/s12276-018-0200-4.

Received: 9 January 2018 Revised: 12 October 2018 Accepted: 16 October 2018.

Published online: 12 February 2019

\section{References}

1. Semenza, G. L. Hypoxia-inducible factor 1 and cancer pathogenesis. IUBMB Life 60, 591-597 (2008)

2. Gordan, J. D. \& Simon, M. C. Hypoxia-inducible factors: central regulators of the tumor phenotype. Curr. Opin. Genet. Dev. 17, 71-77 (2007).

3. Hickey, M. M. \& Simon, M. C. Regulation of angiogenesis by hypoxia and hypoxia-inducible factors. Curr. Top. Dev. Biol. 76, 217-257 (2006).

4. Park, I. H. et al. Constitutive stabilization of hypoxia-inducible factor alpha selectively promotes the self-renewal of mesenchymal progenitors and maintains mesenchymal stromal cells in an undifferentiated state. Exp. Mol. Med. 45, e44 (2013).

5. Erler, J. T. et al. Hypoxia-mediated down-regulation of Bid and Bax in tumors occurs via hypoxia-inducible factor 1-dependent and -independent mechanisms and contributes to drug resistance. Mol. Cell. Biol. 24, 2875-2889 (2004).

6. Engelman, J. A. et al. MET amplification leads to gefitinib resistance in lung cancer by activating ERBB3 signaling. Science 316, 1039-1043 (2007).

7. $\mathrm{Xu}, \mathrm{L}$. et al. Epidermal growth factor receptor regulates MET levels and invasiveness through hypoxia-inducible factor-1alpha in non-small cell lung cancer cells. Oncogene 29, 2616-2627 (2010).

8. Lu, C. W. Lin, S. C., Chen, K. F., Lai, Y. Y. \& Tsai, S. J. Induction of pyruvate dehydrogenase kinase-3 by hypoxia-inducible factor-1 promotes metabolic switch and drug resistance. J. Biol. Chem. 283, 28106-28114 (2008).

9. Comerford, K. M. et al. Hypoxia-inducible factor-1-dependent regulation of the multidrug resistance (MDR1) gene. Cancer Res. 62, 3387-3394 (2002).

10. Semenza, G. L. Hypoxia-inducible factors: mediators of cancer progression and targets for cancer therapy. Trends Pharmacol. Sci. 33, 207-214 (2012).

11. Mabjeesh, N. J. et al. Geldanamycin induces degradation of hypoxia-inducible factor lalpha protein via the proteosome pathway in prostate cancer cells. Cancer Res. 62, 2478-2482 (2002).

12. Ellinghaus, P. et al. BAY $87-2243$, a highly potent and selective inhibitor of hypoxia-induced gene activation has antitumor activities by inhibition of mitochondrial complex I. Cancer Med. 2, 611-624 (2013).

13. Koh, M. Y. et al. Molecular mechanisms for the activity of PX-478, an antitumor inhibitor of the hypoxia-inducible factor-1alpha. Mol. Cancer Ther. 7, 90-100 (2008).

14. Dat, N. T. et al. Hypoxia-inducible factor-1 inhibitory benzofurans and chalcone-derived diels-alder adducts from Morus species. J. Nat. Prod. 72, 39-43 (2009).

15. Kaur, N. et al. The first total synthesis of moracin $O$ and moracin $P$, and establishment of the absolute configuration of moracin O. Chem Commun (Camb). 14, 1879-1881 (2009).

16. Xia, Y., Jin, Y., Kaur, N., Choi, Y. \& Lee, K. HIF-1alpha inhibitors: synthesis and biological evaluation of novel moracin $\mathrm{O}$ and $\mathrm{P}$ analogues. Eur. J. Med. Chem. 46, 2386-2396 (2011).

17. Han, S. P., Tang, Y. H. \& Smith, R. Functional diversity of the hnRNPs: past, present and perspectives. Biochem. J. 430, 379-392 (2010).

18. Moran-Jones, K., Grindlay, J., Jones, M., Smith, R. \& Norman, J. C. hnRNP A2 regulates alternative mRNA splicing of TP53INP2 to control invasive cell migration. Cancer Res. 69, 9219-9227 (2009).

19. Kwon, S., Barbarese, E. \& Carson, J. H. The cis-acting RNA trafficking signal from myelin basic protein mRNA and its cognate trans-acting ligand hnRNP A2 enhance cap-dependent translation. J. Cell Biol. 147, 247-256 (1999). 
20. Ford, L. P., Wright, W. E. \& Shay, J. W. A model for heterogeneous nuclear ribonucleoproteins in telomere and telomerase regulation. Oncogene 21, 580-583 (2002).

21. Moran-Jones, K. et al. hnRNP A2, a potential ssDNA/RNA molecular adapter at the telomere. Nucleic Acids Res. 33, 486-496 (2005).

22. Griffin, M. E. et al. Post-transcriptional regulation of glucose transporter-1 by an AU-rich element in the $3^{\prime} U T R$ and by hnRNP A2. Biochem. Biophys. Res. Commun. 318, 977-982 (2004)

23. Hamilton, B. J. et al. hnRNP A2 and hnRNP $L$ bind the $3^{\prime} U T R$ of glucose transporter $1 \mathrm{mRNA}$ and exist as a complex in vivo. Biochem. Biophys. Res. Commun. 261, 646-651 (1999).

24. Tauler, J., Zudaire, E., Liu, H., Shih, J. \& Mulshine, J. L. hnRNP A2/B1 modulates epithelial-mesenchymal transition in lung cancer cell lines. Cancer Res. 70, 7137-7147 (2010).

25. Han, N., Li, W. \& Zhang, M. The function of the RNA-binding protein hnRNP in cancer metastasis. J. Cancer Res. Ther. 9, S129-S134 (2013). Suppl.

26. Dowling, P. et al. Abnormal levels of heterogeneous nuclear ribonucleoprotein A2B1 (hnRNPA2B1) in tumour tissue and blood samples from patients diagnosed with lung cancer. Mol. Biosyst. 11, 743-752 (2015).

27. Golan-Gerstl, R. et al. Splicing factor hnRNP A2/B1 regulates tumor suppressor gene splicing and is an oncogenic driver in glioblastoma. Cancer Res. $\mathbf{7 1}$ 4464-4472 (2011).

28. Shan, J., Munro, T. P., Barbarese, E., Carson, J. H. \& Smith, R. A molecular mechanism for mRNA trafficking in neuronal dendrites. J. Neurosci. 23 8859-8866 (2003).

29. Masuda, K., Abdelmohsen, K. \& Gorospe, M. RNA-binding proteins implicated in the hypoxic response. J. Cell. Mol. Med. 13, 2759-2769 (2009).

30. Hagele, S., Kuhn, U., Boning, M. \& Katschinski, D. M. Cytoplasmic polyadenylation-element-binding protein (CPEB) 1 and 2 bind to the HIFlalpha mRNA 3'-UTR and modulate HIF-1alpha protein expression. Biochem. J. 417, 235-246 (2009)

31. Galban, S. et al. RNA-binding proteins HuR and PTB promote the translation of hypoxia-inducible factor 1alpha. Mol. Cell. Biol. 28, 93-107 (2008).

32. Wang, R., Zhou, S. \& Li, S. Cancer therapeutic agents targeting hypoxiainducible factor-1. Curr. Med. Chem. 18, 3168-3189 (2011).

33. Unsworth, H., Raguz, S., Edwards, H. J., Higgins, C. F. \& Yague, E. mRNA escape from stress granule sequestration is dictated by localization to the endoplasmic reticulum. FASEB J. 24, 3370-3380 (2010).

34. Jang, M., Kim, S. S. \& Lee, J. Cancer cell metabolism: implications for therapeutic targets. Exp. Mol. Med. 45, e45 (2013).

35. Kim, J., Kim, J. \& Bae, J. S. ROS homeostasis and metabolism: a critical liaison for cancer therapy. Exp. Mol. Med. 48, e269 (2016).

36. Barcelo, C. et al. Ribonucleoprotein HNRNPA2B1 interacts with and regulates oncogenic KRAS in pancreatic ductal adenocarcinoma cells. Gastroenterology 147, 882-892 e8 (2014).

37. Fielding, P., Turnbull, L., Prime, W., Walshaw, M. \& Field, J. K. Heterogeneous nuclear ribonucleoprotein A2/B1 up-regulation in bronchial lavage specimens: a clinical marker of early lung cancer detection. Clin. Cancer Res. 5, 4048-4052 (1999).

38. Patry, C. et al. Small interfering RNA-mediated reduction in heterogeneous nuclear ribonucleoparticule A1/A2 proteins induces apoptosis in human cancer cells but not in normal mortal cell lines. Cancer Res. 63, 7679-7688 (2003).

39. Lee, C. H. et al. Identification of the heterogeneous nuclear ribonucleoprotein A2/B1 as the antigen for the gastrointestinal cancer specific monoclonal antibody MG7. Proteomics 5, 1160-1166 (2005).

40. Zhou, J. et al. Purification and characterization of a protein that permits early detection of lung cancer. Identification of heterogeneous nuclear ribonucleoprotein-A2/B1 as the antigen for monoclonal antibody 703D4. J. Biol. Chem. 271, 10760-10766 (1996).

41. Clower, C. V. et al. The alternative splicing repressors hnRNP A1/A2 and PTB influence pyruvate kinase isoform expression and cell metabolism. Proc. Natl Acad. Sci. USA 107, 1894-1899 (2010).

42. Han, J. et al. Mechanisms underlying regulation of cell cycle and apoptosis by hnRNP B1 in human lung adenocarcinoma A549 cells. Tumori 100, 102-111 (2014).

43. He, Y., Brown, M. A., Rothnagel, J. A., Saunders, N. A. \& Smith, R. Roles of heterogeneous nuclear ribonucleoproteins $A$ and $B$ in cell proliferation. J. Cell Sci. 118, 3173-3183 (2005).

44. Arango, D. et al. Molecular basis for the action of a dietary flavonoid revealed by the comprehensive identification of apigenin human targets. Proc. Natl Acad. Sci. USA 110, E2153-E2162 (2013).

45. Cockman, M. E. et al. Hypoxia inducible factor-alpha binding and ubiquitylation by the von Hippel-Lindau tumor suppressor protein. J. Biol. Chem. 275, 25733-25741 (2000).

46. Kim, H. J. et al. Mutations in prion-like domains in hnRNPA2B1 and hnRNPA1 cause multisystem proteinopathy and ALS. Nature 495, 467-473 (2013).

47. Martinez, F. J. et al. Protein-RNA Networks Regulated by Normal and ALSAssociated Mutant HNRNPA2B1 in the Nervous System. Neuron 92, 780-795 (2016).

48. Decker, C. J. \& Parker, R. P-bodies and stress granules: possible roles in the control of translation and mRNA degradation. Cold Spring Harb. Perspect. Biol. 4, a012286 (2012).

49. Hu, B. R. \& Wieloch, T. Stress-induced inhibition of protein synthesis initiation: modulation of initiation factor 2 and guanine nucleotide exchange factor activities following transient cerebral ischemia in the rat. J. Neurosci. 13, 1830-1838 (1993)

50. Durut, N. \& Saez-Vasquez, J. Nucleolin: dual roles in rDNA chromatin transcription. Gene 556, 7-12 (2015).

51. Koutsioumpa, M. \& Papadimitriou, E. Cell surface nucleolin as a target for anticancer therapies. Recent Pat. Anticancer Drug Discov. 9, 137-152 (2014).

52. Shahab, S., Shamsi, T. S. \& Ahmed, N. Prognostic involvement of nucleophosmin mutations in acute myeloid leaukemia. Asian Pac. J. Cancer Prev. 14 5615-5620 (2013). 